\title{
RDA Implementation in Large US Public Libraries
}

\section{Chris Evin Long}

This survey sought to investigate how the transition to the new cataloging standard, Resource Description and Access (RDA), has been handled in one hundred of the largest US public libraries, specifically examining whether catalogers believe that some of RDA's major goals have been met, and how some of the anticipated impacts of RDA implementation have been handled. A large majority of these libraries have implemented RDA for original cataloging, but respondents also generally believe that $R D A$ has failed to meet some of its most important goals, primarily ease of use and cost-effectiveness.

$\mathrm{T}$ he international cataloging community began an epic journey in June 2011 when the Library of Congress (LC), the National Library of Medicine (NLM), and the National Agricultural Library (NAL) announced that they planned to conditionally adopt Resource Description and Access (RDA), the new cataloging standard developed by the Joint Steering Committee for Development of RDA (JSC). Prior to the US national libraries' official implementation of RDA on March 31, 2013, several American libraries had already adopted it for their own use. The Program for Cooperative Cataloging (PCC) took a differentiated approach to RDA implementation, setting separate deadlines for the mandatory use of RDA in authority and bibliographic records. The PCC established March 31, 2013, as the date after which all new authority records entering the LC Name Authority File (LCNAF) had to be coded as RDA, but PCC libraries were allowed to continue to use the Anglo-American Cataloguing Rules, Second Edition (AACR2) for bibliographic records until December 31, 2014. All libraries that subsequently ingested the new records created by LC, PCC libraries, and other early adopters thus became de facto implementers of RDA, whether or not they had approved of the new standard.

RDA's developers sought to achieve a number of goals with the new standard. One of its primary objectives was to be responsive to users' needs, enabling them to fulfill the Functional Requirements for Bibliographic Records' (FRBR) objectives of finding, identifying, selecting, obtaining, and understanding information about resources and agents relevant to their research needs. ${ }^{1}$

Providing effective bibliographic control for all types of resources, which AACR2 lacked, was deemed as a key component in meeting this objective. RDA specifically includes instructions to help catalogers better describe the types of materials acquired by twenty-first-century libraries, particularly nonprint, nontextual, and unpublished resources. ${ }^{2}$ Furthermore, RDA's increased reliance on cataloger judgment in applying instructions was aimed at attaining a greater focus on local user needs. ${ }^{3}$ In addition to users' needs, consideration was given to how RDA would be used and implemented by libraries and their edu) is the Head of Monographic and Special Materials Cataloging at the University of Colorado Boulder.

Manuscript submitted October 8, 2017; returned to author for revision November 28, 2017; revision submitted January 5, 2018; accepted for publication March 28, 2018. cataloging practitioners. Cost-effectiveness and continuity were some of RDA's 
major design objectives. RDA metadata records must be produced in a cost-effective manner and compatible with existing records in online catalogs, particularly those developed using AACR2 and related standards. ${ }^{4}$ Moreover, the intent was for RDA to be clearly written and easy to use and interpret, with numerous examples provided that are appropriate and relevant to specific instructions. ${ }^{5}$ Finally, RDA was intentionally published as a web-based toolkit to incorporate the features and functionality of online access. ${ }^{6}$

Catalogers have had several years to apply RDA and assess its impact both on their own practices and their users. While there have been numerous post-implementation studies of RDA within individual libraries and national cataloging communities, most have focused primarily on training issues and changes to the local integrated library system (ILS) necessary to accommodate RDA elements and the corresponding new MARC fields. To date, however, there has been a paucity of research examining whether catalogers believe that RDA has met its stated purposes and goals. Furthermore, in studies where library type is the study's emphasis, the RDA research conducted thus far has concentrated primarily on academic libraries with scant regard for public libraries, despite the fact there are 2.4 times as many public libraries as academic libraries in the United States. ${ }^{7}$ This paper intends to fill both of these knowledge gaps by investigating how the transition to RDA has been handled in large US public libraries since LC/PCC's implementation, specifically using a survey that examined whether public library catalogers believe some of RDA's major goals have been met and how some of the anticipated impacts of RDA implementation have been handled. For instance, since one of RDA's goals was to provide effective bibliographic control for all types of resources, are catalogers in large public libraries using it to describe all the types of resources owned or acquired by their libraries? What have been the effects of RDA implementation on public library systems and cataloging procedures? How effectively are catalogers able to use and interpret RDA? How is ongoing RDA training being conducted? What are the general perceptions of cataloging managers in large public libraries regarding the costeffectiveness of implementing RDA? Are these libraries using the online RDA Toolkit or accessing RDA some other way? The results of this survey can inform cataloging practitioners, public library administrators, professional organizations, and the RDA Steering Committee (RSC). For catalogers and administrators, the topics examined can provide a benchmark of practice, enabling them to see how their peers have handled various RDA issues. Professional organizations and national library agencies can see where more training is needed. For the RSC, it is hoped that the results point out aspects of RDA that can be improved.

\section{Literature Review}

Librarians, particularly catalogers, who worked in the early twenty-first century will well remember the vast amount of information disseminated about RDA during its development phase. Since the history of RDA's development and its philosophical underpinnings are already well examined in the literature, this review focuses on the implementation aspects of RDA specifically examined in the survey.

\section{Pre-implementation Research}

\section{Training}

Well before the US national libraries decided to implement RDA, librarians were grappling with how to understand it; much of the early literature on RDA focused on explaining the new cataloging standard and critiquing its merits. ${ }^{8}$ As RDA coalesced and its application became imminent, the literature began shifting attention to implementation issues. In this pre-adoption period, training in the new cataloging code was widely identified as the most pressing need for a successful RDA implementation. One of the earliest papers to address this was by Hitchens and Symons, who emphasized the need to use a number of educational formats to deliver the training content, including both online education and in-person conferences and workshops. ${ }^{9}$ Numerous national-level surveys and reports from libraries that participated in the initial RDA testing program buttressed the Hitchens and Symons assessment, generally agreeing that a wide variety of training methods should be made available. Many of the respondents reported a heavy reliance on online learning, especially LC's free training materials, supplemented by a steady diet of in-house, hands-on instruction. ${ }^{10}$ That catalogers were largely dependent on free online education is not surprising, since Sanchez's 2011 email survey found that funding for training was a serious concern for more than 60 percent of the respondents. ${ }^{11}$ Tosaka and Park noted "it appears that the RDA training landscape currently remains fairly fragmented-characterized by the duplication of ad hoc efforts among various library organizations and continuing education providers," presenting catalogers with a wide, but perhaps bewildering, array of training options. ${ }^{12}$ On the cusp of LC's RDA implementation in March 2013, these same authors in a separate study observed that the "low levels of familiarity reported for a wide range of RDA topics were rather alarming."

\section{Perceptions of RDA}

Not all pre-adoption RDA implementation research centered on training-considerable effort was also made to 
gauge what catalogers thought of the new code. General impressions of RDA tended to be influenced by the amount of direct experience respondents had with the code. Respondents to Sanchez's 2011 survey, most of whom were from were from small- to medium-sized libraries, showed that uncertainty, resignation, distrust, and anxiety towards RDA were common attitudes. ${ }^{14}$ Surveys conducted by the US RDA Test Coordinating Committee and Young and Bross, however, showed that catalogers who had actually worked with RDA were far more positive about it, leading them to conclude that negative perceptions would likely dissipate with more RDA practice. ${ }^{15}$

\section{Anticipated Impact on Users and Catalogers}

The long buildup to RDA's publication also allowed ample time to speculate on matters related to RDA's goals and purposes that have an impact on end users, catalogers, and library managers. Several aspects of RDA's responsiveness to users' needs were examined in the literature. Beall's finding that users most often prefer full spellings over abbreviations, affirmed by some of the RDA test participants, supported RDA's decision to avoid abbreviations whenever possible. ${ }^{16}$ Issues surrounding RDA's replacement of the General Material Designation (GMD) with what was intended to be more precise terms for content, carrier, and media types (CMCs) were also studied. Hider found that although end users recognized the new RDA terms for the CMCs, they did not always interpret them as RDA had intended.$^{17}$ Catalogers who participated in RDA testing also had negative reactions to the abandonment of the GMD, questioning whether the new terminology and vocabulary used in RDA would be intuitive enough to end users, and in general they mostly believed that RDA records were not easier to understand than their AACR2 predecessors. ${ }^{18}$ The imminent loss of the GMD was debated by the librarians at Central Connecticut State University, who feared it would negatively affect their users. Ultimately, they decided they would not locally add GMDs to RDA records but would also suppress the new 33X fields in their public display. ${ }^{19}$ Pre-adoption impressions about RDA's cost-effectiveness were mixed. More than half of Sanchez's survey participants doubted that RDA would be cost effective. ${ }^{20}$ Cronin, while acknowledging there would be costs involved for training and preparing the ILS to implement and display the new RDA fields, was hopeful that the RDA Toolkit could provide savings in the long term. ${ }^{21}$ Regarding RDA's promise of simplifying cataloging rules, Intner allowed that RDA better supported cataloger judgment than AACR2 but did not conclude that it was simpler to apply, an assertion that was later affirmed by some RDA test participants. ${ }^{22}$

\section{Anticipated Impact on ILS Systems and Cataloging Procedures}

Cronin's 2011 paper discussing the University of Chicago's experience in adopting RDA considered the impact of its implementation on ILS systems and copy cataloging procedures. Library systems would need to accommodate the increased emphasis on the use of relationship designators in MARC records. Furthermore, cataloging managers would need to manage the integration of RDA records with AACR2 records and determine which RDA elements might need to be added to existing AACR2 records. Cronin addressed the issues surrounding the replacement of the GMD with the new CMCs and opined that cataloging managers would need to consider a number of options. Should RDA data be mapped in the ILS to harmonize its data values with corresponding ones in the GMD? Should GMDs be removed from public displays altogether? Should libraries do nothing to alter either RDA or AACR2 records and let existing GMDs continue to display to catalog users? ${ }^{23}$ The latter view was supported by Central Connecticut State University, which decided not to modify existing AACR2 records to resemble their RDA counterparts. ${ }^{24}$ Other authors also pondered implementation issues. Hunt and Danskin provided guidance on things to consider when preparing the ILS for RDA adoption, while a study by McCutcheon reported that Kent State University staff found RDA records to be compatible with AACR2 records in both the staff and public modes. ${ }^{25}$

\section{Post-implementation Research \\ Training}

As libraries followed the US national libraries and made their own RDA implementation decisions, research from practitioners continued to proliferate. A number of individual institutions related their own adoption decisions, several national surveys reported on issues faced in their countries, and studies of how RDA was being implemented in specific types of libraries were conducted. ${ }^{26}$ Perhaps not surprisingly, training continued to be an area of great concern, particularly the attendant costs, as several authors commented on the continuing need for affordable education options. ${ }^{27}$ Consequently, many institutions relied heavily on LC's free training materials. ${ }^{28}$ Preferred methods of training were scrutinized, and in-house and in-person training was often viewed as a valuable complement to online offerings. ${ }^{29}$ Some authors noted that the overabundance of different versions of online training materials from LC and other organizations created confusion. ${ }^{30}$ Lack of training materials for nonbook and foreign language materials was perceived as problematic. ${ }^{31}$ 


\section{Adoption Rates}

A number of national-level surveys documented RDA adoption rates in their respective countries or regions. In Canada, university libraries had the highest rate of partial adoption of RDA, while college, government, and special libraries reported high rates of non-adoption. ${ }^{32}$ Ducheva and Pennington reported that high costs were a common barrier to adoption in some European countries, while Brazil found RDA to be incongruent with its cataloging traditions. ${ }^{33}$ Technical difficulties were also cited as an impediment. ${ }^{34}$ Several papers noted the importance of existing national library structures and cataloging policies in aiding RDA adoption in some European countries, while the lack thereof in Turkey created difficulties. ${ }^{35}$ The levels of adoption within individual libraries also varied. Choi, Yusof, and Ibrahim reported that staff at the National Library Board Singapore cataloged solely in RDA, regardless of whether it was original or copy cataloging. ${ }^{36}$ RMIT University in Melbourne also decided to upgrade AACR2 copy to RDA and programmatically revised incoming copy cataloging records to conform as closely to RDA as possible. ${ }^{37}$ The libraries of Kent State University and Concordia University, in contrast, chose to do original cataloging in RDA but to still accept AACR2 copy cataloging records. ${ }^{38}$

\section{GMD Questions}

Discussion involving the replacement of the GMD with the new CMCs persisted in the post-adoption literature, much of which concentrated on its impact on users. Columbia University's librarians were not convinced that the vocabularies used in these fields were comprehensible enough for users to identify the right resource format. ${ }^{39}$ Likewise, RMIT University's public services staff were not enthusiastic about the CMC terms, and the library decided not to display these fields. ${ }^{40}$ Concordia University Libraries tried to ameliorate this problem by implementing additional icons to help end users identify resources in the desired format. ${ }^{41}$

Libraries were also confronted with format-related public display issues. Caudle and Schmitz reported that Auburn University tried to use the CMCs to display format information in their VuFind catalog, but were disappointed to find that RDA lacked the necessary granularity, and they resorted to using format data from other MARC fields. ${ }^{42}$ Jin and Sandberg found that none of the public display options in the University of Illinois at Urbana-Champaign Library ILS fully supported RDA. ${ }^{43}$ The Z. Smith Reynolds Library at Wake Forest University encountered similar problems when personnel experimented with using CMCs to enhance discovery faceting. Although they judged the CMCs to be more granular and specific than GMDs, they found that "CMCs alone do not provide for sufficiently robust faceting of public catalog searches," primarily because of their ILS's limitations and the MARC format. ${ }^{44}$ Other libraries addressed the issue by hybridizing catalog records, with some adding GMDs to their RDA records and many others retrospectively adding the 33X fields to their AACR2 records. ${ }^{45}$ Mississippi State University's catalogers took this approach one step further, concluding that retaining GMDs was the best way to support user tasks, but also determined that an even more effective solution was to update legacy GMD terms with more item-specific terms. They reviewed the GMD vocabulary to develop a list of "common terms" to replace the more general GMD terms. For example, terms such as "DVD" or "VHS" were substituted for the more general GMD "videorecording."

\section{Perceptions of RDA}

Overall, post-adoption perceptions of RDA were mixed. Some characterized RDA as an important tool and lauded the flexibility it allowed for cataloging decisions, its suitability for describing digital and nonprint library resources, and its straightforward instructions. ${ }^{47}$ Parent reported that some of RMIT University's staff were uncomfortable with such freedom and were eager to see clear guidelines established. ${ }^{48}$ Tosaka concluded, "Ultimately, it seems reasonable to conclude that RDA has not yet made our daily cataloging work any easier in the current implementation environment, with added time and energy needed for staff training and revising local workflows, for example, without immediate visible improvements in users' resource discovery experience." ${ }^{\prime 9}$

\section{Public Library Cataloging Research}

The paucity of literature that examines cataloging in public libraries is stark in its contrast to the scholarly attention paid to the academics. A smattering of papers spread out over decades, however, sheds some light. Freedman and Bishoff both maintained that responsiveness to local user needs is imperative in public library cataloging. ${ }^{50}$ Bierman asserted that the speed with which materials are made available to users is of utmost importance. ${ }^{51}$ McGurr, Mason, and Monaco observed that public libraries catalog a large variety of materials, with a special emphasis on nonprint resources like music CDs and DVDs, and concur with Bierman that they are expected to process material quickly. ${ }^{52}$ In one of the few studies that discuss public library catalogers' behavior, Miksa's 2008 survey of North Texas public libraries revealed a low usage of cataloging tools and resources such as AACR2, Cataloger's Desktop, and manuals like the MARC21 format manuals. ${ }^{53}$ Lambert, Panchyshyn, and McCutcheon's 2013 paper is the only one thus far that focuses specifically on RDA implementation 
in public libraries. They contend that significant new developments are often adopted later in public libraries, a position buttressed by their finding that almost one-third of Ohio public library catalogers had not heard of RDA as of a 2012 survey. ${ }^{54}$ Given public library catalogers' focus on their community and the necessity for speedy cataloging of materials in a diverse array of formats and accessible tools, it would seem that a cataloging code like RDA that is intended to be easy to use and interpret, promotes effective bibliographic control for all types of media, is focused on local users' needs, and is accessible and cost effective would be readily embraced.

\section{Method}

The most recent survey database of the Institute of Museum and Library Services' Public Libraries Survey (at the time FY 2014) was used to determine the hundred largest public libraries in the United States as determined by overall collection size. Excluded from this group were three PCC libraries since RDA implementation for those libraries is dictated by PCC policies. Also excluded were two libraries that outsourced or decentralized cataloging operations, so that cataloging practices for a specific library could not be determined. Five libraries with the next largest collections were therefore included in their stead. The collections of the selected libraries ranged in size from $8,391,595$ to 973,236; these counts reflect the data gathered by the Public Libraries Survey and include print materials, e-books, audio and video physical units, and audio and video downloadable files. The survey population was limited to a hundred libraries for two reasons. First, it was assumed that libraries of such size would have the number of catalogers able to provide original cataloging and would collect the amount of materials needing original cataloging that would provide a valid assessment of RDA's effectiveness. The second reason was more practical. It was a surprisingly difficult and time-consuming process to find email addresses for technical services librarians, catalogers, or even library directors in the targeted public libraries. Consequently, the author decided to limit the population to a hundred so that the survey could be conducted in a timely manner.

The research was conducted using an electronically administered survey, created using Qualtrics survey software. The survey's scope was limited to bibliographic records; respondents were not asked about RDA authority work. The survey questions addressed the following topics:

- the library's RDA original and copy cataloging practices;

- the effects of RDA on the library's ILS;

- access to RDA by the library;
- training;

- perceptions of ease of use and cost-effectiveness; and

- RDA’s impact on local cataloging practices.

Responses were solicited by direct email from persons identified through the libraries' websites as those most likely to be knowledgeable about the organization's cataloging practices and were typically heads of technical services or cataloging managers. When contact information was available only for library directors or associate directors, they were requested to pass on the survey to the most appropriate person in the library. Survey content was pre-tested with several public library cataloging managers, and survey format and navigation were pre-tested with librarians and cataloging staff at the University of Colorado Boulder. The hundred solicitations were distributed on February 20, 2017, with reminder emails sent to nonrespondents on February 28 and March 8. The survey closed on March 12. Fifty respondents started the survey and forty-five completed it. The results for the uncompleted surveys were not considered in the study, so the response rate was 45 percent (forty-five respondents).

\section{Findings Demographics}

The survey began with two demographical questions. Respondents were asked to indicate their library's geographic region according to their Office of Business Economics (OBE) region code. Most of the largest US public libraries are in the Far West, followed in descending order by the Southeast, the Middle East, the Great Lakes, and Southwest states. The Plains, Rocky Mountains, and New England regions have considerably lower representation, although the exclusion of PCC libraries somewhat depleted the total for New England. In general, the geographic distribution of respondents closely matched that of the survey population as a whole (see table 1).

Respondents were then asked how many full-time equivalent (FTE) employees performed some sort of cataloging duties as part of their jobs, broken down by:

- professional salaried employees (MLS/MLIS degree required);

- salaried library employees (MLS/MLIS degree not required); and

- hourly employees (non-salaried, MLS/MLIS degree not required)

The average number of professional employees is 2.77 , with reported totals ranging from a high of nine to a low of 
Table 1. Geographic Distribution of Survey Population and Respondents.

\begin{tabular}{lcc}
\hline Region & $\begin{array}{c}\text { Survey Population } \\
(\boldsymbol{n}=\mathbf{1 0 0 )}\end{array}$ & $\begin{array}{c}\text { Survey Respondents } \\
(\boldsymbol{n}=\mathbf{4 5})\end{array}$ \\
Far West (AK CA HI NV OR WA) & $24(24 \%)$ & $11(24.4 \%)$ \\
Southeast (AL AR FL GA KY LA MS NC SC TN VA WV) & $21(21 \%)$ & $9(20 \%)$ \\
Mid East (DE DC MD NJ NY PA) & $16(16 \%)$ & $8(17.8 \%)$ \\
Great Lakes (IL IN MI OH WI) & $15(15 \%)$ & $7(15.6 \%)$ \\
Southwest (AZ NM OK TX) & $11(11 \%)$ & $5(11.1 \%)$ \\
Plains (IA KS MN MO NE ND SD) & $7(7 \%)$ & $5(11.1 \%)$ \\
Rocky Mountains (CO ID MT UT WY) & $4(4 \%)$ & $0(0 \%)$ \\
\hline New England (CT ME MA NH RI VT) & $2(2 \%)$ & $0(0 \%)$ \\
\hline
\end{tabular}

and the resulting records harder for our patrons to use, not easier." A participant offered these withering sentiments: "As a public library, our customers are not conversant with library jargon and certainly not with 'catalog-ese.' Nothing in RDA is relevant to the end-user, our tax-paying, bond-voting, library card-carrying public. Cataloging obfuscates information from the general public and is only relevant to zero, with thirteen libraries (29 percent) reporting one. Support staff slightly outnumber librarians, with an average of 2.81. Support staff FTE numbers varied from seventeen to zero, with eleven libraries (24 percent) reporting the latter. The average number of hourly employees (1.33) was almost half of the other two ranks, with a high of five and twentythree libraries (51 percent) reporting zero. One library's report of 360 hourly cataloging FTEs was assumed to be an error and was not counted in the average for that rank.

\section{RDA and Original Cataloging}

The survey next asked about the library's use of RDA for original cataloging, and 78 percent $(n=35)$ of the respondents reported that they have fully adopted it for original cataloging of some bibliographic formats. Of that group, twenty-nine reported that they use RDA to create original records for all types of bibliographic resources. The remaining six libraries were asked about the specific types of resources for which they use RDA in original cataloging. Not surprisingly, print monographs are the predominant format, followed distantly by sound recordings and videorecordings. When asked why RDA is not used for certain formats, responses included reasons such as lack of training (particularly for specialized formats), incompatibility with the discovery layer, and that very little original cataloging is done for formats other than print monographs.

There remains an appreciable percentage of nonadopters within the survey population. The ten libraries that reported that RDA has not been implemented for any original cataloging were asked to provide an explanation. The most common reason cited was that RDA is difficult for patrons to understand. One respondent commented, "Many aspects of RDA make it more difficult for patrons and staff in public libraries to access material." Another offered a similar observation: "RDA is a 'disimprovement' as a cataloging system . . . RDA's basis in FRBR, a set of theoretical mathematics principles, makes both the cataloging process those in the profession." The focus on users' needs as a reason for non-adoption stands in contrast to that found in the literature review, which cited rationales such as the prohibitive costs of RDA implementation, conflict with cataloging traditions, and technical issues. ${ }^{55}$

There were other justifications as well, including:

- RDA implementation is not a priority within the library;

- there was a managerial decision to not implement RDA;

- little original cataloging is done in the library;

- and, staff training would be needed.

The non-adopting libraries were then asked about future plans to adopt RDA for original cataloging. The answers were mixed, with four libraries indicating that they definitely or probably will, another four ambivalently stating that they might, and the remaining two stating that they probably or definitely will not.

\section{RDA and Copy Cataloging}

Participants were then queried about RDA and their institution's copy cataloging practices. The survey first inquired whether RDA additions or revisions are made to AACR2 records, and then conversely asked if any AACR2 additions or revisions are made to RDA records. In both cases, respondents who answered affirmatively were asked about the types of changes made and how they are done.

Twenty-six libraries (58 percent) replied that no RDA changes are made to AACR2 records, while nineteen (42 percent) answered that they are. The most common revision was the addition of the 33X fields, following closely by spelling out abbreviations and changing the MARC publication field from 260 to 264. Adding relationship designators to access points and removing GMDs are less common modifications (see table 2). 
One respondent mentioned that his institution deletes all unique RDA fields and has instructed their vendors to follow this pattern when supplying customized records. Having catalogers make these modifications at the time of cataloging is by far the most frequent method employed, with some commenters noting that their catalogers do this programmatically using MarcEdit and OCLC macros and text strings. Applying ILS processes like global updates and using vendor services are less frequent approaches, although most libraries employed a combination of these procedures (see table 3).

The reverse scenario, making AACR2related modifications to RDA records, is slightly more common, with a little over half of the respondents $(n=23,51$ percent) answering affirmatively. The most frequent revision is the addition of GMDs to RDA records. Notably, all libraries except for one that add GMDs also retain the 33X fields. A small number of libraries remove the $33 \mathrm{X}$ fields or the relationship designators from access points (see table 4).

As with RDA-related modifications to AACR2 records, having catalogers make these changes at the point of cataloging is the overwhelmingly preferred method used (see table 3). This hybridization of catalog records, mixing AACR2 and RDA elements to achieve desired results for search and discovery, closely aligns with the findings of previous studies. ${ }^{56}$

\section{RDA's Effects on the ILS}

As previously noted, it was anticipated that RDA would present librarians with a number of ILS issues to consider, including how to utilize and display the new CMCs and how to cope with the increased presence of relationship designators in RDA records. Survey participants were asked if they retain the 33X fields, and forty (89 percent) responded affirmatively. Those who answered yes were asked whether they display the 33X fields in the public view of their ILS and if so, which fields. Twenty-seven (68 percent) of this group indicated that, even though they retain the fields, they do not display them. Nine of the remaining thirteen libraries answered that they show all of them, while four responded that only some of the fields are visible. Of these four libraries, all display the 338 carrier types (e.g., volume, video disc, online resource), while three display the 336 content types (e.g., text, still image, performed music) and two display the 337 media types (e.g., unmediated, computer, video). Regarding use of CMCs to identify a resource's format in the public view of the ILS (as an icon, in faceting, etc.), only a small segment $(n=5,12$ percent) reported that they do this. This reluctance to display CMCs to the public and use them in faceting reflects similar practices discussed in the literature review. ${ }^{57}$ When polled about the retention and display of relationship designators, the survey showed that while a large majority of libraries $(n=36,80$ percent) retain them, a smaller portion $(n=23$, 68 percent) actually display them to the public.

\section{Persistence of the GMD}

The GMD was a recurring topic in much of the previous research on RDA implementation, and this survey revealed that it is still far from dead in large public library catalogs. As noted earlier, the questions on RDA and copy cataloging disclosed that many catalogers in the survey group are hesitant to remove the GMD from incoming AACR2 records, and in 
fact a significant number actively insert them into RDA copy cataloging records. This trend also holds true for original cataloging practices; eighteen libraries reported that they add GMDs to original catalog records in their local ILS, while seventeen indicated that they do not.

The previous section revealed that, while most libraries retain the $33 \mathrm{X}$ fields, few display them to the public or use them to indicate a resource's format. In contrast, a substantial majority ( $n$ $=38,84$ percent) opted to retain the GMD in their legacy AACR2 records, and thirty-three members of that group (87 percent) continue to display it to their users. Clearly, many public library catalogers still champion the GMD's utility, and survey comments indicate

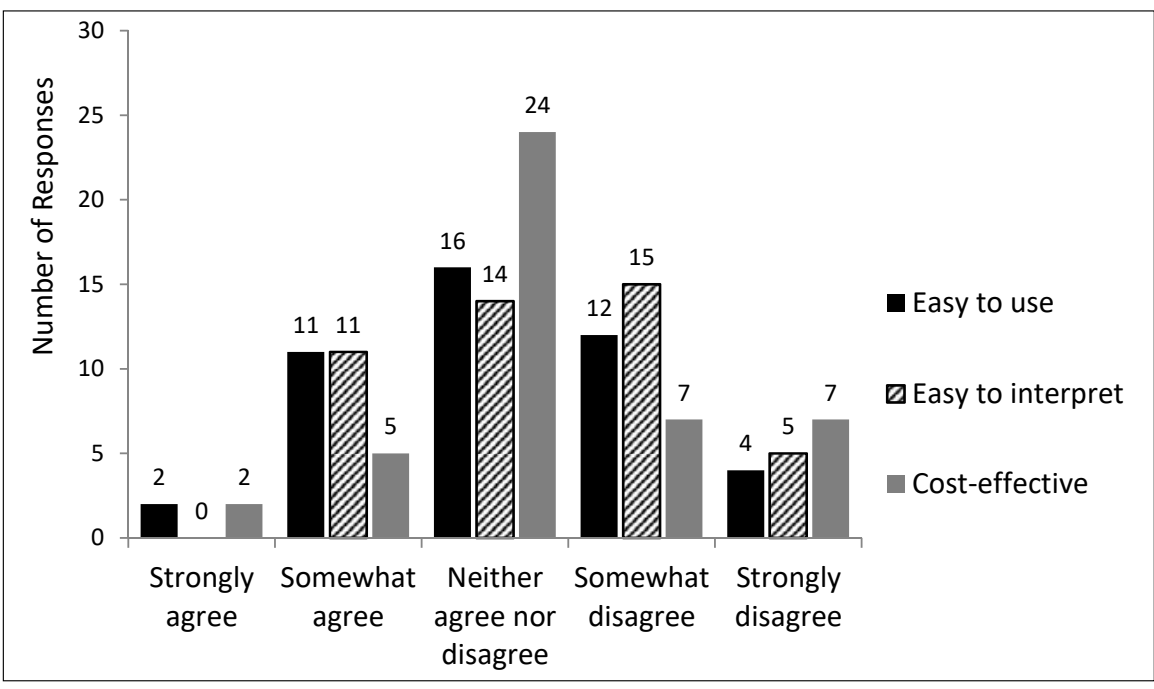

Figure 1. Do Catalogers Find That RDA Is Easy to Use and Interpret, and Is Cost-Effective?

that concern for their users is a key motivating factor. One participant stated, "We laboriously add GMDs into all outside records in order to provide better customer service and access for our patrons." Other representative remarks included: "The 33X fields are useless and the elimination of the GMD is very problematic" and "Our librarians and service staff prefer the GMD.” Public library catalogers' perception that the GMD still benefits users is similar to opinions of other catalogers expressed in previous research. ${ }^{58}$

\section{Modes of Access to RDA}

RDA was intentionally developed as an online tool, and that is how it is predominantly being used in large public libraries. Thirty-seven libraries in the group access RDA through the online RDA Toolkit and almost all $(n=34)$ do so through a single institutional subscription; only two libraries reported that they participate in a consortial or group subscription. The online RDA Toolkit is the sole means of access for the majority of respondents $(n=32,73$ percent). Eleven libraries (25 percent) also use the print version of RDA; six of these libraries use the print version in tandem with the online Toolkit, while print is the sole means of access for five libraries. One library indicated that it uses the e-book version in addition to print. The seven libraries that do not use the RDA Toolkit cited reasons such as ease of use, cost, and difficulties in gaining access.

\section{Catalogers' Perceptions of Using RDA and Its Cost-Effectiveness}

A primary goal of RDA was for it to be clearly written and easy to use and interpret. A majority of large public library catalogers are either uncertain if this goal has been met or definitely think it has not. Survey participants were asked to rate their level of agreement as to whether their institution's catalogers find RDA easy to use and interpret. Most of the respondents displayed ambivalence, neither agreeing nor disagreeing, while similar numbers either somewhat or strongly disagreed that RDA is easy to use and interpret. In both cases, agreement of any kind, cautious or strong, is the minority opinion. The survey did not delve into the reasons underlying these perceptions, but comments made throughout the survey indicate that much of the difficulty catalogers experience using RDA is related to the $R D A$ Toolkit's structure. Survey respondents opined that it is not well organized (particularly in comparison to AACR2), is cumbersome to navigate, and would benefit from the addition of a user manual and index.

Cost-effectiveness was another of RDA's major objectives, but large public library cataloging managers are not convinced that this objective has been achieved. When asked to what extent they thought that RDA is a costeffective way to support user tasks, over half neither agreed nor disagreed. Almost a third $(n=14)$ responded negatively, answering "somewhat disagree" or "strongly disagree" in equal numbers. Only two participants (4 percent) replied that they "strongly agree" and another five (11 percent) said they "agree" with this assertion (see figure 1).

When asked about the costliest aspects of implementing RDA, the cost of the RDA Toolkit subscription (eleven responses) and training (ten responses) were the two primary concerns cited. Modifications to bibliographic records are also considered a significant expense by seven libraries, whether the changes involved making records more RDA-compliant (e.g., by adding the CMCs) or by making AACR2-related revisions (e.g., adding GMDs and deleting relationship designators). These actions are considered 


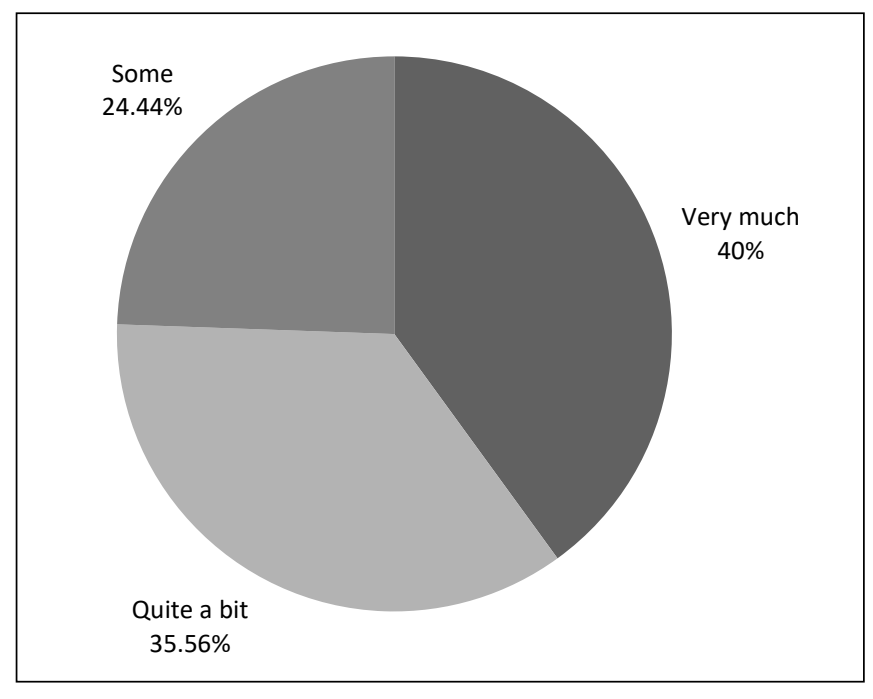

Figure 2. Extent to Which Catalogers Exercise Cataloger's Judgment.

costly in terms of both money and time, whether this work is done manually by staff or by vendors.

\section{RDA's Impact on Local Cataloging Policy}

RDA endeavored to be more focused on local end users' needs by allowing for more cataloger judgment. Given Freedman's and Bishoff's previously stated contention that responsiveness to local user needs is imperative in public library cataloging, it is logical to assume that catalogers in the survey population would welcome the increased freedom offered by RDA. The results show that this is unequivocally the case. When asked to indicate the extent to which catalogers in their institution are encouraged to exercise cataloger judgment, eighteen (40 percent) indicated "always," sixteen (36 percent) answered "very often," and eleven (24 percent) responded "some." No participants replied "very little" or "none" (see figure 2).

Nevertheless, the desire for clear guidelines observed in her staff by Parent is also evident in the survey results. Participants were asked to indicate how frequently their catalogers follow the LC/PCC Policy Statements. Over half of the people who answered this question $(n=22)$ reported that staff do this "very often," with another 10 percent $(n=4)$ indicating that it is done "always" and 17 percent $(n=7)$ saying it is done "often." The remaining 20 percent $(n=8)$ responded either "sometimes" or "never" in equal numbers (see figure 3).

\section{Ongoing RDA Training}

Training has been the predominant implementation issue addressed in the RDA literature to date. The cost of

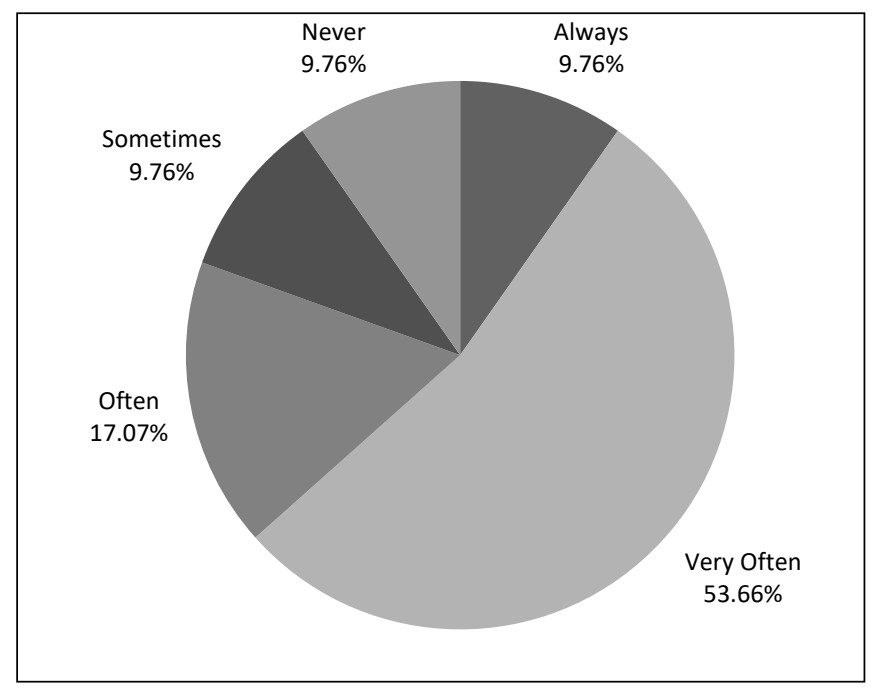

Figure 3. Extent to Which Catalogers Follow LC/PCC Policy Statements.

educating staff was worrisome to cataloging managers, both in terms of money and time. Other concerns were the lack of available instruction for some formats and confusion caused by the multiplicity of different versions of training materials. The survey findings show that these hindrances remain for many catalogers.

When asked how ongoing RDA training is being conducted, the results showed a mixture of formal and informal methods. Training materials or workshops conducted either in person or online by professional organizations other than LC was the most prevalent answer. Email discussion lists, blogs, social media, etc. received the next highest number of replies, closely followed by personnel from the respondents' own institutions. In contrast to previous research, relatively few institutions use the LC/PCC training materials. Other means of training cited were YouTube videos and using existing bibliographic records as exemplars (see table 5).

The question about ongoing training was followed by an inquiry into training obstacles respondents experienced. Four libraries indicated that they have encountered no impediments, but many more enumerated the ongoing challenges they face. In keeping with issues identified in previous studies, cost and lack of staff time to devote to training were regularly cited by respondents as abiding dilemmas, particularly in the face of heavy workload demands. Difficulty understanding RDA concepts, particularly regarding its relationship with FRBR and MARC, and low priority for training within the institution were reported several times. The frequency of change in RDA instructions was an oft-cited problem. One respondent encapsulated the sentiments of many by stating, "RDA is also just difficult to understand and seems to be constantly changing so it's hard to keep up." Guidance in applying RDA for specialized 
formats like media resources is still seen as a neglected area of instruction. The largest number of complaints, however, involve the inadequacy of RDA educational offerings and the lack of advanced training. Participants repeatedly bemoaned the basicness of most RDA workshops and the prevalence of conflicting information from different trainers. One respondent stated, "Most training webinars/classes still cover extreme basics and make it a waste of time to hear 'how RDA came to be' over and over again. We've had enough of the 'why' and now we need the "how to." Another asserted, "It's also hard to find very good quality training. I don't need someone to read manuals to me, I need clear guidance on 'how do I catalog this thing in RDA with all of the appropriate MARC fields."”

The plea for more and better training continued to resonate in the survey responses. Participants were asked what assistance they need to help them learn more about RDA. A few respondents indicated that they need no help, while others simply said that more experience in using RDA will suffice. Many more, though, expressed the need for help and suggested a number of solutions. Not surprisingly, free or inexpensive training is the biggest request, although the desired mode varied, with some respondents asking for online offerings and others wanting in-person opportunities. Several people sought guidance in handling special formats and complex cataloging situations like compilations and revised editions, while others called for simplified RDA instructions, more and better examples, and additional direction on how to code RDA in MARC. The necessity for improved current awareness channels, particularly for RDA updates and new MARC fields, was frequently mentioned, as was more support from ILS vendors on how implemented RDA within local systems.

\section{Conclusion}

Restricting the survey population to the one hundred largest public libraries in the United States limits the generalizability of this study's findings. It does not capture the behavior and attitudes of catalogers in other types or sizes of US libraries or libraries in other countries. However, it does provide a record of RDA implementation practices and catalogers' perceptions of its efficacy in a sizeable but understudied segment of American libraries, and it does so on the eve of a major redesign and restructuring of the RDA Toolkit.

Over three-fourths of the largest US public libraries have adopted RDA for original cataloging, but a sizeable minority of them have not done so and seem unlikely to do so soon. Most of the adopters are using the new cataloging code to provide original cataloging for all types of resources, which is in line with its goal of providing effective bibliographic control for all types of media, but in some libraries, its use in cataloging formats such as serials, nonprint materials, and online resources lags far behind that of print monographs. Survey responses suggest this is likely due to the lack of training for special formats. In accordance with the RDA developers' original intent, most of these libraries use the online Toolkit rather than other options. Catalogers in these institutions also employ the greater degree of cataloger judgment that RDA affords in support of their strong focus on local user needs.

This study also shows that these libraries have grown comfortable with hybrid records, regularly adding new bibliographic elements introduced by RDA to AACR2 records, particularly the CMCs. However, they do not accept that the CMCs provide library users with more granular access to a resource's format type and are reluctant to stop using GMDs, which many libraries retain in AACR2 records, add to RDA records, and display in their ILS's public view. In contrast, while virtually all the respondent libraries retain the CMCs in their bibliographic records, few use them to identify formats in their public display.

Nevertheless, the survey results clearly show that large US public library catalogers believe RDA has failed to meet some of its most important goals, primarily ease of use and cost-effectiveness. Most catalogers in this group do not agree that RDA is easy to use and interpret, much of which they attribute to inadequacies in the RDA Toolkit's structure and the lack of good examples. It is hoped that the RSC heeds this counsel as it restructures the toolkit. Respondents also said that they often struggle to comprehend underlying RDA concepts and to remain current with constantly changing rules and best practices. Better training could be an antidote for these ailments, but catalogers report many challenges in receiving this instruction, not just in terms of direct costs and staff time, but also in the 
lack of advanced guidance. While LC and professional organizations have amassed a wealth of RDA training resources, it is time to move instruction beyond the basics.

This study suggests some potential directions for future research. In the short term, other types and sizes of libraries could be examined to determine if the practices and perceptions of RDA and its implementation by catalogers in large US public libraries are unique to them or are more generalizable. In the longer term, after catalogers have had an opportunity to learn and apply the newly restructured RDA Toolkit, this survey could be replicated to see if they believe improvements have been made.

\section{References}

1. RDA Steering Committee, "RDA: Resource Description and Access," section 0.0, accessed August 25, 2017, http://access .rdatoolkit.org.

2. Cooperative and Instructional Programs Division, Library of Congress, "Library of Congress Training for RDA: Resource Description \& Access, Module 1," accessed August 25, 2017, www.loc.gov/catworkshop/RDA\%20training\%20 materials/LC\%20RDA\%20Training/Module1IntroManifest ItemsSept12.doc.

3. Library of Congress, "SCCTP Basic Serials Cataloging Workshop," 2014, accessed August 25, 2017, www.loc.gov /aba/pcc/conser/scctppt/Basic-2014/Basicl-Background.pptx.

4. RDA Steering Committee, "RDA: Resource Description and Access," section 0.3.1.

5. Joint Steering Committee for Development of RDA, "RDA Prospectus," accessed August 25, 2017, www.rda-jsc.org /archivedsite/rdaprospectus.html.

6. Library of Congress, "Library of Congress Training for RDA: Resource Description \& Access, Module 1."

7. American Library Association, "ALA Library Fact Sheet 1," accessed August 25, 2017, www.ala.org/tools/libfactsheets /alalibraryfactsheet01.

8. Amy Hart, The RDA Primer: A Guide for the Occasional Cataloger (Santa Barbara, CA: Linworth, 2010); Chris Oliver, Introducing RDA: A Guide to the Basics (Chicago: American Library Association, 2010); Mary Beth Weber and Fay Angela Austin, Describing Electronic, Digital, and Other Media Using AACR2 and RDA: A How-To-Do-It Manual and CD-ROM for Librarians (New York: Neal-Schuman, 2011); Diane I. Hillmann, "RDA for Who?," Technicalities 26, no. 3 (2006): 8-10; Karen Coyle and Diane Hillmann, "Resource Description and Access (RDA): Cataloging Rules for the 20th Century," D-Lib Magazine 13, no. 1-2 (2007), https://doi.org/10.1045/january2007-coyle.

9. Alison Hitchens and Ellen Symons, "Preparing Catalogers for RDA Training," Cataloging \& Classification Quarterly 47, no. 8 (2009): 691-707, https://doi.org/10.1080 /01639370903203234.

10. US RDA Test Coordinating Committee, "Report and Recommendations of the US RDA Test Coordinating Committee," 2011, accessed August 25, 2017, http://www.loc.gov/bib liographic-future/rda/source/rdatesting-finalreport-20june 2011.pdf; TSIG RDA Training Needs Assessment Working
Group, "Summary of the Survey Conducted by TSIG RDA Training Needs Assessment Working Group,” 2011, accessed August 25, 2017, http://rdaincanada.wikispaces.com/Survey; Chris Todd, Charlotte Stretton, and Janess Stewart, "RDA Training Needs Survey (New Zealand),” 2010, http://nznuc -cataloguing.pbworks.com/w/page/26673174/RDA\%20training \%20needs\%20analysis; Deirdre Kiorgaard, "RDA Training Needs Survey (Australia)," 2010, accessed August 25, 2017, www.nla.gov.au/lis/stndrds/grps/acoc/documents/training surveyaust.doc; Alan Danskin, "RDA in the UK: Summary of Survey Results," (presentation, CILIP Cataloguing and Indexing Group Conference, Exeter, UK, September 13, 2010), www.ukoln.ac.uk/events/CIG/2010/conf-exeter/pro gramme; Christopher Cronin, "From Testing to Implementation: Managing Full-Scale RDA Adoption at the University of Chicago," Cataloging \& Classification Quarterly 49, no. 7-8 (2011): 626-46, https://doi.org/10.1080/01639374.2011 .616263 .

11. Elaine R. Sanchez, "RDA, AACR2, and You: What Catalogers Are Thinking," in Conversations with Catalogers in the 21st Century, ed. Elaine R. Sanchez (Santa Barbara, CA: Libraries Unlimited, 2011), 20-70.

12. Yuji Tosaka and Jung-ran Park, "RDA: Resource Description \& Access-A Survey of the Current State of the Art," Journal of the American Society for Information Science \& Technology 64, no. 4 (2013): 659.

13. Yuji Tosaka and Jung-ran Park, "RDA: Training and Continuing Education Needs in Academic Libraries," Journal of Education for Library \& Information Science 55, no. 1 (2014): 3-25.

14. Sanchez, "RDA, AACR2, and You," 20-70.

15. US RDA Test Coordinating Committee, "Report and Recommendations," Jennifer B. Young and Valerie Bross, "Results of the CRCC Informal RDA Testing Task Force," Cataloging \& Classification Quarterly 49, no. 7-8 (2011): 600-606, https://doi.org/10.1080/01639374.2011.620223.

16. Jeffrey Beall, "Abbreviations, Full Spellings, and Searchers' Preferences," Cataloging \& Classification Quarterly 49, no. 6 (2011): 443-456, https://doi.org/10.1080/01639374.2011.5 95886; Cronin, "From Testing to Implementation," 626-46.

17. Philip Hider, "A Comparison Between the RDA Taxonomies and End-User Categorizations of Content and Carrier," Cataloging \& Classification Quarterly 47, no. 6 (2009): 
544-60, https://doi.org/10.1080/01639370902929755; Philip Hider, "Library Resource Categories and Their Possible Groupings," Australian Academic \& Research Libraries 40, no. 2 (2009): 105-15, https://doi.org/10.1080/00048623.200 9.10721389 .

18. Cronin, "From Testing to Implementation," 626-46; US RDA Test Coordinating Committee, "Report and Recommendations."

19. Dana Hanford, "A Look at How We Got Here: RDA Implementation at Central Connecticut State University, Journal of Library Metadata 14, no. 3-4 (2014): 152-65, https://doi .org/10.1080/19386389.2014.977725.

20. Sanchez, "RDA, AACR2, and You," 20-70.

21. Cronin, "From Testing to Implementation," 626-46.

22. Sheila S. Intner, "Taking a Look at the Draft RDA.," Technicalities 29, no. 2 (2009): 1, 16-17; Cronin, "From Testing to Implementation," 626-46.

23. Cronin, "From Testing to Implementation," 626-46.

24. Hanford, "A Look at How We Got Here," 152-65.

25. Stuart Hunt, "RDA in Your ILS," Catalogue and Index 169 (2012): 22-24; Alan Danskin, "Implementing RDA at the British Library," CILIP Update with Gazette April (2014): 40-41; Sevim McCutcheon, "RDA Testing in Triplicate: Kent State University's Experiences with RDA Testing," Cataloging \& Classification Quarterly 49, no. 7-8 (2011): 607-25, https://doi.org/10.1080/01639374.2011.616262.

26. Doğan Atılgan, Nevzat Özel, and Tolga Çakmak, "Awareness, Perceptions, and Expectations of Academic Librarians in Turkey about Resource Description and Access (RDA)," Cataloging \& Classification Quarterly 52, no. 6-7 (2014): 66076, https://doi.org/10.1080/01639374.2014.945023; Doğan Atılgan, Nevzat Özel, and Tolga Çakmak, "RDA in Turkey: Perceptions and Expectations on Implementation," Italian Journal of Library, Archives, \& Information Science 6 (2015): 163-79; Adam Baron, "Implementing Resource Description and Access (RDA)," Argus (Montreal, Quebec) 42, no. 3 (2014): 58-61; Renate Behrens, Christine Frodl, and Renate Polak-Bennemann, "The Adoption of RDA in the GermanSpeaking Countries," Cataloging \& Classification Quarterly 52, no. 6-7 (2014): 688-703, https://doi.org/10.1080 /01639374.2014.882872; Dana M. Caudle and Cecilia Schmitz, "Keep It Simple: Using RDA’s Content, Media, and Carrier Type Fields to Simplify Format Display Issues," Journal of Library Metadata 14, no. 3-4 (2014): 222-38, https://doi.org/10.1080/19386389.2014.984572; Kathy Choi, Haslinda Md Yusof, and Fauziah Ibrahim, "RDA: National Library Board Singapore's Learning Journey," Cataloging d Classification Quarterly 52, no. 6-7 (2014): 608-20, https:// doi.org/10.1080/01639374.2014.891165; Emma Cross et al., "In the Company of My Peers: Implementation of RDA in Canada," Cataloging \& Classification Quarterly 52, no. 6-7 (2014): 747-74, https://doi.org/10.1080/01639374.2014.8995 35; Danskin, "Implementing RDA at the British Library,"
40-41; Dilyana Ducheva and Diane Pennington, "RDA in Europe: Implementations and Perceptions," Journal of Librarianship \& Information Science (2016); Qiang Jin and Jane A. Sandberg, "Implementing RDA at the University of Illinois at Urbana-Champaign Library," Technical Services Quarterly 31, no. 3 (2014): 217-36, https://doi.org/10 .1080/07317131.2014.908585; Frank P. Lambert, Roman S. Panchyshyn, and Sevim McCutcheon, "Resource Description and Access and Ohio Public Libraries," Public Library Quarterly 32, no. 3 (2013): 187-203, https://doi.org/10.10 80/01616846.2013.818497; Margaret Beecher Maurer and Roman S. Panchyshyn, "Understanding the Why: A Case Study in Managing the RDA Implementation," Cataloging \& Classification Quarterly 52, no. 3 (2014): 259-84, https://doi. org/10.1080/01639374.2013.859644; Carolyn McCallum et al., "Can RDA Content, Media, and Carrier Coding Improve Discovery Facet Mapping?, Library Resources \& Technical Services 61, no. 2 (2017): 93-101; Carol Ou and Sean Saxon, "Displaying Content, Media, and Carrier Types in the OPAC: Questions and Considerations," Journal of Library Metadata 14, no. 3-4 (2014): 239-54, https://doi.org/10.10 80/19386389.2014.990846; Melissa Parent, "Implementing RDA in a Time of Change: RDA and System Migration at RMIT University," Cataloging \& Classification Quarterly 52, no. 6-7 (2014): 775-96, https://doi.org/10.1080/0163937 4.2014.889058; Jung-ran Park and Yuji Tosaka, "RDA Implementation and Training Issues across United States Academic Libraries: An In-Depth E-mail Interview Study," Journal of Education for Library bInformation Science Online 56, no. 3 (2015): 252-76; Amy H. Turner, "RDA Training and Implementation at Duke University Libraries: Minimizing the Distraction," Journal of Library Metadata 14, no. 2 (2014): 69-76, https://doi.org/10.1080/19386389.2014 .909671; Melanie Wacker, Myung-ja Han, and Judith Dartt, "Testing Resource Description and Access (RDA) With Non-MARC Metadata Standards," Cataloging \& Classification Quarterly 49, no. 7-8 (2011): 655-75, https://doi.org/10 $.1080 / 01639374.2011 .616451$.

27. Lambert, Panchyshyn, and McCutcheon, "Resource Description and Access and Ohio Public Libraries," 187 203; Cross et al., "In the Company of My Peers," 747-74; Turner, "RDA Training and Implementation at Duke University Libraries," 69-76.

28. Danskin, "Implementing RDA at the British Library," 40-41; Jin and Sandberg, "Implementing RDA at the University of Illinois at Urbana-Champaign Library," 217-36; Turner, "RDA Training and Implementation at Duke University Libraries," 69-76.

29. Park and Tosaka, "RDA implementation and Training Issues across United States Academic Libraries," 252-76; Cross et al., "In the Company of My Peers," 747-74.

30. Park and Tosaka, "RDA Implementation and Training Issues," 252-76; Choi, Yusof, and Ibrahim, "RDA: National 
Library Board Singapore's Learning Journey," 608-20.

31. Park and Tosaka, "RDA implementation and Training Issues," 252-76; Turner, "RDA Training and Implementation at Duke University Libraries," 69-76.

32. Cross et al., "In the Company of My Peers," 747-74.

33. Ducheva and Pennington, "RDA in Europe: Implementations and Perceptions."

34. Atılgan, Özel, and Çakmak, "Awareness, Perceptions, and Expectations of Academic Librarians in Turkey," 660-76.

35. Behrens, Frodl, and Polak-Bennemann, "The Adoption of RDA in the German-Speaking Countries," 688-703; Atılgan, Özel, and Çakmak, "RDA in Turkey," 163-79.

36. Choi, Yusof, and Ibrahim, "RDA: National Library Board Singapore's Learning Journey," 608-20.

37. Parent, "Implementing RDA in a Time of Change," 1-22.

38. Maurer and Panchyshyn, "Understanding the Why," 259-84; Baron, "Implementing Resource Description and Access (RDA)," 58-61.

39. Wacker and Han, "Testing Resource Description and Access (RDA)," 655-675.

40. Parent, "Implementing RDA in a Time of Change," 1-22.

41. Baron "Implementing Resource Description and Access (RDA)," 58-61.

42. Caudle and Schmitz, "Keep It Simple," 222-38.

43. Jin and Sandberg, "Implementing RDA at the University of Illinois," 217-36.

44. McCallum et al., "Can RDA Content, Media, and Carrier Coding Improve Discovery Facet Mapping?," 93-101.

45. Ou and Saxon, "Displaying Content, Media, and Carrier Types in the OPAC," 239-54; Behrens, Frodl, and Polak-Bennemann, "The Adoption of RDA in the GermanSpeaking Countries,” 688-703.

46. James Kalwara, Melody Dale, and Marty Coleman, "GMD or No GMD: RDA Implementation for a Consortial Catalog," Library Resources \& Technical Services 61, no. 3 (2017): 162-70.

47. Atılgan, Özel, and Çakmak, "RDA in Turkey," 163-79; Susan R. Morris and Beacher Wiggins, "Implementing RDA at the Library of Congress," Italian Journal of Library \& Information Science 7, no. 2 (2016): 199-228; Turner, "RDA Training and Implementation," 69-76.

48. Parent, "Implementing RDA in a Time of Change," 1-22.
49. Yuji Tosaka, "RDA: Resource Description \& AccessReports from the Field," Journal of Library Metadata 14, no. 3-4 (2014): 150, https://doi.org/10.1080/19386389.2014 .993249 .

50. Maurice J. Freedman, "Some Thoughts on Public Libraries and the National Bibliographic Network," Journal of Library Automation 10, no. 2 (1977): 120-30; Lizbeth J. Bishoff, "Who Says We Don't Need Catalogers?," American Libraries 18, no. 8 (1987): 694-96.

51. Kenneth J. Bierman, "Technical Services in Public Libraries," Journal of Library Administration 15, no. 1-2 (1991): 115-23, https://doi.org/10.1300/J111v15n01_08.

52. Melanie McGurr, Catherine Mason, and Michael Monaco, "Public and Academic Library Cataloging Collaboration in Ohio's NACO Funnel Project," Cataloging \& Classification Quarterly 51, no. 1-3 (2012): 72-81, https://doi.org/10.1080 /01639374.2012.734368.

53. Shawne D. Miksa, "A Survey of Local Library Cataloging Tool and Resource Utilization," Journal of Education for Library \& Information Science 49, no. 2 (2008): 128-46.

54. Lambert, Panchyshyn, and McCutcheon, "Resource Description and Access," 187-203.

55. Ducheva and Pennington, "RDA in Europe: Implementations and Perceptions;" Atılgan, Özel, and Çakmak, "Awareness, Perceptions, and Expectations of Academic Librarians in Turkey," 660-76.

56. Parent, "Implementing RDA in a Time of Change," 1-22; Maurer and Panchyshyn, "Understanding the Why," 259-84; Baron, "Implementing Resource Description and Access (RDA)," 58-61; Ou and Saxon, "Displaying Content, Media, and Carrier Types in the OPAC," 239-54; Behrens, Frodl, and Polak-Bennemann, "The Adoption of RDA in the German-Speaking Countries,” 688-703.

57. Wacker and Han, "Testing Resource Description and Access (RDA)," 655-75; Parent, "Implementing RDA in a Time of Change," 1-22; Caudle and Schmitz, "Keep It Simple," 222 38; McCallum et al., "Can RDA Content, Media, and Carrier Coding Improve Discovery Facet Mapping?, 93-101.

58. Ou and Saxon, "Displaying Content, Media, and Carrier Types in the OPAC," 239-54; Kalwara, Dale, and Coleman, "GMD or No GMD: RDA Implementation for a Consortial Catalog," 162-70.

\section{Appendix. Survey Questions-RDA Implementation in Large Public Libraries}

You are invited to take part in a brief research survey about how the transition to Resource Description and Access (RDA) has been handled in large U.S. public libraries. To protect the integrity of the data, the survey can only be completed once. However, if you cannot complete the survey in one sitting, you may close it and resume it at a later time. The survey will close on March 12.
Your participation will require approximately ten minutes. The survey questions deal with: original and copy cataloging; the effects of RDA on your ILS; access to RDA; ease of use, training, and cost-effectiveness; and RDA's impact on local cataloging.

There are no known risks or discomforts associated with this survey. Taking part in this study is completely 
voluntary. If you choose to be in the study you can withdraw at any time without adversely affecting your relationship with anyone at the University of Colorado Boulder. Your responses will be kept strictly confidential, and digital data will be stored in secure computer files. Any report of this research that is made available to the public will not include your name or any other individual information by which you could be identified.

If you have questions or want a copy or summary of this study's results, you can contact the researcher, Chris Long, at chris.long@colorado.edu. Please feel free to print a copy of this consent page to keep for your records.

Clicking the "Next" button below indicates that you are 18 years of age or older, and indicates your consent to participate in this survey.

\section{Demographics}

1. Please indicate the region in which your institution is located.

_ New England (CT ME MA NH RI VT)

_ Mid East (DE DC MD NJ NY PA)

- Great Lakes (IL IN MI OH WI)

- Plains (IA KS MN MO NE ND SD)

- Southeast (AL AR FL GA KY LA MS NC SC TN VA WV)

_ Southwest (AZ NM OK TX)

- Rocky Mountains (CO ID MT UT WY)

- Far West (AK CA HI NV OR WA)

2. How many FTE employees have some cataloging duties as part of their job?

_ Professional salaried employees (MLS/MLIS degree required)

_ Paraprofessional salaried employees (MLS/ MLIS degree not required)

_ Hourly employees (non-salaried, MLS/MLIS degree not required)

\section{RDA and Original Cataloging}

3. Has your library adopted Resource Description and Access (RDA) for original cataloging of any bibliographic formats?

- Yes

- No

(If yes, go to Question \#6. If no, go to Question \#4.)

4. What is your institution's reason(s) for not adopting RDA for original cataloging?

5. Does your library plan to adopt RDA for original cataloging in the future?

Definitely yes

_ Probably yes
_ Might or might not

_ Probably not

— Definitely not

(Skip to Question \#10.)

6. Do the catalogers in your institution create original records for all types of resources using RDA?

- Yes

- No

(If yes, go to Question \#9. If no, go to Question \#7.)

7. For which types of resources are your catalogers creating original records using RDA? Please select all that apply.

Print monographs

_ Print serials

_ Ebooks

_ Ejournals

_ Sound recordings

_ Videorecordings

_ Scores

_ Maps

— Rare materials

— Websites

_ Unpublished materials

- Other (Please specify)

8. What is your institution's reason(s) for not using RDA in the original cataloging of certain formats?

9. In your local integrated library system (ILS), do you add General Material Designations (GMDs) to original records that you create?

- Yes

- No

\section{RDA and Copy Cataloging}

10. For copy cataloging, do the catalogers in your institution make any RDA additions or revisions to AACR2 records? Examples of this might include adding MARC 336, 337, and 338 fields, spelling out abbreviations, etc. - Yes

- No

- Don't know

(If yes, go to Question \#11. If no or don't know, go to Question \#13.)

11. What additions or revisions do they make? Please check all that apply.

Add MARC 336, 337, and 338 fields

_ Spell out abbreviations

_ Change MARC field 260 to 264

— Add relationship designators to access points

— Remove General Material Designations (GMDs)

— Other? Please explain. 
12. How are the elements added or removed? Please check all that apply.

By catalogers at the time of cataloging

— Through integrated library system (ILS) global updates or a similar process

_ By a vendor service

- Other? Please explain.

13. Conversely, do the catalogers at your institution make any AACR2 additions or revisions to RDA records? Examples of this might include removing MARC 336, 337, and 338 fields, adding General Material Designations (GMDs) to records, etc.

- Yes

- No

- Don't know

(If yes, go to Question \#14. If no or don't know, go to Question \#16.)

14. What additions or revisions do you make? Please check all that apply.

_ Remove MARC 336, 337, and 338 fields

_ Remove relationship designators from access points

- Add General Material Designations (GMDs)

_ Other? Please explain.

15. How are the elements added or removed? Please check all that apply.

By catalogers at the time of cataloging

— Through ILS global updates or a similar process

— By a vendor service

_ Other? Please explain.

\section{RDA's Effects on the Integrated Library System (ILS)}

16. Has your library retained the General Material Designations (GMDs) in your legacy AACR2 records?

- Yes

- No

- Don't know

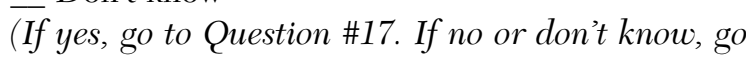
to Question \#18.)

17. Does your library display GMDs in the public view of your ILS?

Yes

- No

- Don't know

18. Does your library retain the MARC 336, 337, and 338 fields in RDA records that you use?

- Yes

- No

- Don't know

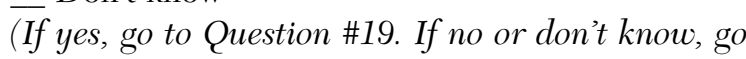
to Question \#22.)
19. Does your library display the MARC 336, 337, and 338 fields in the public view of your ILS?

Yes, all of them

— Yes, but only some of them

- No

- Don't know

(If yes, but only some of them, go to Question \#20. Otherwise, go to Question \#21.)

20. Which 33X fields do you display? Please check all that apply.

_ 336 (content type)

_ 337 (media type)

_ 338 (carrier type)

21. Does your library use the $33 \mathrm{X}$ fields in some way (as an icon, in faceting, etc.) to identify a resource's format in the public view of your ILS?

_ Yes

- No

_ Don't know

22. Does your library retain the relationship designators (generally found in subfield "e" of the 1XX and 7XX MARC fields) in RDA records that you use?

- Yes

- No

— Don't know

(If yes, go to Question \#23. If no or don't know, go to Question \#24.)

23. Does your library display the relationship designators in the public view of your integrated library system (ILS)?

- Yes

- No

Don't know

\section{Access to RDA}

24. Does your library have online access to the RDA Toolkit?

- Yes

- No

- Don't know

(If yes, go to Question \#25. If no or don't know, go to Question \#26.)

25. Please indicate how you subscribe to the RDA Toolkit.

_ Institutional subscription

_ Consortial or group subscription

Don't know

(Skip to Question \#27.)

26. What are your institution's reasons for not using the RDA Toolkit? Please check all that apply.

_ Cost

_ Ease of use

_ Don't know

_ Other? Please explain. 
27. Do the catalogers in your institution access RDA in a way other than the Toolkit? Please check all that apply.

Yes, the print version

Yes, the e-book version

- No

— Don't know

\section{Using RDA}

28. Please rate the extent to which you agree or disagree with the following statement: The catalogers in my library find RDA easy to use.

_ Strongly agree

_ Somewhat agree

— Neither agree nor disagree

_ Somewhat disagree

— Strongly disagree

29. Please rate the extent to which you agree or disagree with the following statement: The catalogers in my library find RDA easy to interpret.

_ Strongly agree

— Somewhat agree

— Neither agree nor disagree

— Somewhat disagree

_ Strongly disagree

\section{RDA Training}

30. How is your institution's ongoing RDA training conducted? Please check all that apply.

_ Library of Congress/Program for Cooperative Cataloging training materials

_ Training materials or workshops conducted by other professional organizations (either inperson or online)

_ Personnel from your institution

_ Email listservs, blogs, social media, etc.

_ Other? Please explain.
31. What training obstacles have you experienced?

32. What do you believe you need to help you learn more about RDA?

\section{RDA's Impact on Local Cataloging}

33. Please indicate the extent to which the catalogers in your institution follow the LC/PCC Policy Statements.

_ Always

- Very often

— Often

- Sometimes

- Never

Don't know

34. Please indicate the extent to which the catalogers in your institution are encouraged to exercise cataloger's judgment.

— Very much

_ Quite a bit

_ Some

— Very little

- None

— Don’t know

\section{Cost-Effectiveness of RDA}

35. What has been the costliest part(s) of implementing RDA?

36. Please rate the extent to which you agree or disagree with the following statement: RDA is a cost-effective way to support user tasks (finding, identifying, selecting, obtaining, and understanding resources).

Strongly agree

— Somewhat agree

_ Neither agree nor disagree

— Somewhat disagree

_ Strongly disagree 